\title{
The expression of matrix metalloproteinase 9 and cathepsin $B$ in gastric carcinoma is associated with lymph node metastasis, but not with postoperative survival
}

\author{
Jolanta Czyżewska1, Katarzyna Guzińska-Ustymowicz², Andrzej Kemona², \\ Roman Bandurski ${ }^{3}$ \\ ${ }^{1}$ Department of Clinical Laboratory Diagnostics, Medical University of Białystok, Poland \\ ${ }^{2}$ Department of General Pathomorphology, Medical University of Białystok, Poland \\ ${ }^{3}$ Department of General Surgery and Gastroenterology, Medical University of Białystok, Poland.
}

\begin{abstract}
Degradation components of basement membrane could be crucial for tumor invasion. A key role in this process has been assigned to cysteine proteases, i.e. cathepsins and matrix metalloproteinases. The purpose of this study was to investigate the relationship of the expression of MMP-9 and cathepsin B with tumor aggressiveness expressed by lymph node metastases and survival rates in gastric carcinoma patients. Slides of $5 \mu \mathrm{m}$-thick serial sections from 91 patients with primary gastric carcinoma were prepared and analyzed for MMP-9 and cathepsin B expression using anti-human monoclonal antibody (NCL-MMP-9 clone; dilution 1:40 and NCL-CATH-B clone; dilution 1:40). The patients were clinically monitored for 84 months. We found no association between the expression of MMP-9 and cathepsin B in main mass of tumor and patients' gender, tumor location, Lauren's classification or histological differentiation. Also no correlation was observed between the expression of MMP-9 in main mass of tumor and depth of invasion. A strong statistically significant association was found between the expression of MMP-9 and cathepsin B in main mass of tumor and lymph node involvement ( $p<0.001 ; p<0.001$, respectively). However, we observed no correlation between the expression of MMP-9 and cathepsin $\mathrm{B}$ in main mass of tumor and lymph node involvement or 5-year overall survival. Our results may suggest that the expression of matrix metalloproteinase-9 (MMP-9) and cathepsin B is correlated with lymph node metastasis in advanced gastric carcinoma, but not with patients' postoperative survival.
\end{abstract}

Key words: Gastric carcinoma - Matrix metalloproteinase 9 - MMP-9 - Cathepsin B - Survival time

\section{Introduction}

In the process of tumor invasion and metastasis, damage to the surrounding tissues, such as the extracellular matrix (ECM), the basement membrane and the vascular walls, plays a key role [1]. To form metastasis, tumor cells invade through the basement membrane barrier in the proteolytic process of the ECM components [2]. Many proteolytic enzymes are involved in this process, including matrix metalloproteinases (MMPs), cysteine and serine proteases [1].

Correspondence: J. Czyżewska, Dept. of Clinical Laboratory

Diagnostics, Medical University of Białystok,

Waszyngtona Str. 15a, 15-274 Bialystok, Poland;

tel.: (+4885) 7485942, fax.: (+4885) 7485990,

e-mail: czyzyk15@op.pl
Matrix metalloproteinases (MMPs), including MMP-2 and MMP-9, belong to the family of enzymes which degrade the extracellular matrix, and facilitate tumor invasion and spread [3,4]. MMPs are secreted as non-active forms of proenzymes which have to be activated to exert an effect on the extracellular matrix. Tissue inhibitors of metalloproteinases (TIMPs), produced by the host or tumor cells, block latent active MMPs and help prevent the invasion of tumor cells [5].

MMPs are assigned on the basis of the in vitro substrate specificity of the respective metalloproteinases to three groups: collagenases, gelatinases and streomelisins [6,7]. Gelatinases, mainly MMP-2, degrading the basement membrane components seem to play a role at the initial stage of tumor invasion, while other MMPs cooperate at a later stage of the invasion [8]. 
MMP-9 (92- kDa, gelatinases, type IV collagenase) is a member of the family of the MMP genes that damage the ECM through type IV collagen degradation [9] and promote tumor cell invasion. The expression of this protein has been observed in tumors of various organs, including prostate carcinoma, brain carcinoma, melanoma, lymphoma and pancreatic carcinoma [1015]. In renal carcinoma, MMP-9 expression has been shown to be associated with unfavorable prognosis[16]. In gastric carcinoma, this expression is related to such clinico-pathological factors as TNM staging, lymphatic invasion and tumor invasion depth [17].

Cathepsin B (Cath B), a member of a large family of cysteine proteases of the papain type, exhibits a potential to destroy laminin - a basement membrane protein [18]. High cathepsin B activity has been observed in gastric carcinoma in comparison to the adjacent normal mucous membrane. Moreover, the activity of cathepsin B has been found to increase in tumors metastasizing to lymph nodes [19]. High levels of cathepsin B have not only been detected from the tumor [20,21], but also from the serum and urine of gastric carcinoma patients [22]. A correlation has been observed between the expression of cathepsin B and high-grade carcinomas, including breast carcinoma [23,24], lung carcinoma [25] and colorectal carcinoma [26]. The expression of cathepsin B in cancer tissue is related to more aggressive behavior and higher metastasis potential [27].

The aim of the study was to assess the correlation of the expression of MMP-9 and cathepsin B in gastric carcinoma with chosen clinico-pathological parameters and survival time.

\section{Materials and methods}

Collection of samples. The study group consisted of 91 chosen patients with advanced gastric cancer ( 29 women and $62 \mathrm{men}$ ). The mean age was 62 years (range $30-83$ ). The group of patients were clinically monitored for a 84 months.

In all cases, specimens were obtained from the main mass of tumor and metastatic lymph nodes. The specimens were fixed in $10 \%$ buffered formaldehyde and embedded in paraffin. Sections, 5 $\mu \mathrm{m}$ thick, were cut and stained with hematoxylin-eosin.

Immunohistochemistry. The sections were deparaffinized in three changes of xylene and hydrated through an alcohol series of a decreasing concentration. For detection of MMP-9 and cathepsin B proteins, the sections were heated to $95^{\circ} \mathrm{C}$ for $15 \mathrm{~min}$ in citrate buffer $(10 \mathrm{mmol} / \mathrm{l})$ and incubated with $0.5 \%$ hydrogen peroxide solution in methanol for $15 \mathrm{~min}$ and with monoclonal antibodies (NCL-MMP-9, Novocastra Laboratories, dilution 1:40) for all night at $4^{\circ} \mathrm{C}$ and cathepsin B (NCL-CATH-B, Novocastra Laboratories, dilution 1:40) for 120 minutes in room temperature. Novostain Super ABC Kit (NCL- ABCm, Novocastra Laboratories Ltd, UK) was applied as a detection kit. The antigen-antibody complex was visualized by DAB chromogen (S3000, DAKO, Poland).

Evaluation of samples. Protein expression was assessed using a semi-quantitative method and defined as follows:

- Low expression- when there was no reaction or less than $30 \%$ of cells in main mass of tumor and lymph node metastasis were MMP-9 and cathepsin B positive.
- High expression - when more than $30 \%$ of cancer cells in main mass of tumor and lymph node metastasis were MMP-9 and cathespsin B positive

The percentage of MMP-9 and cathepsin B positive cells was calculated in 500 cancer cells in each preparation, at magnification of 400x (by two independent pathologists).

Statistical analysis. Statistical analysis was based on test $\chi^{2}$ and exact Fisher's test. The $\mathrm{p}<0.05$ was considered statistically significant. Multivariate Cox regression analysis was done to evaluate the 5 -year overall survival.

\section{Results}

\section{Expression of MMP-9 and chosen clinico-pathological parameters in main mass of tumor and in lymph node metastasis (Table 1)}

High expression of MMP-9 in main mass of tumor was found in 38 patients and in 22/27 cases of lymph node involvement. The expression was localized in the cytoplasm of cancer cells (Fig. 1). Statistical analysis revealed no correlation of MMP-9 expression in primary tumor and lymph node metastasis with patients' gender, tumor location, invasion depth, Lauren's classification or histological differentiation. MMP-9 in primary tumor was present in $27 / 27(100 \%)$ tumors metastasizing to lymph nodes.

\section{Expression of cathepsin $B$ and chosen clinico-pathological parameters in main mass of tumor and lymph node invasion (Table 2)}

The expression of cathepsin B was observed in cellular cytoplasm (Fig. 2). Statistical analysis showed a correlation of tumor cathepsin B expression with lymph node involvement and invasion depth. However, such parameters as patients' gender, tumor location, Lauren's classification and histological differentiation were not found to correlate with cathepsin B expression by tumor or metastasis.

\section{Expression of MMP-9 and cath $B$ vs. postoperative survival time of patients}

In our study, the mean survival time in patients with high tumor expression of MMP-9 was 84 months, as compared to those with low expression - 60 months. Moreover, in the group of high MMP-9 expression, the mortality rate was increased between the 2nd-10th month. However, it was not statistically significant (Fig. 3).

The mean survival time of patients with tumor cathepsin B expression was approximately 60 months, being 84 months in cathepsin B-negative group. In the former group, higher mortality rate was observed 
Table 1. Expression of MMP9 and chosen clinical and pathological parameters in main mass of tumor and in lymph node metastasis.

\begin{tabular}{|c|c|c|c|c|c|c|}
\hline \multirow{2}{*}{ Parameters } & \multicolumn{3}{|c|}{$\begin{array}{l}\text { Expression of MMP9 } \\
\text { in main mass }\end{array}$} & \multicolumn{3}{|c|}{$\begin{array}{l}\text { Expression of MMP9 } \\
\text { in lymph node metastasis }\end{array}$} \\
\hline & Low $(n=53)$ & High $(n=38)$ & $\mathrm{p}$ & Low $(n=5)$ & High $(n=22)$ & $\mathrm{p}$ \\
\hline \multicolumn{7}{|c|}{ Sex } \\
\hline Female & $16(55,2 \%)$ & $13(44,8 \%)$ & \multirow{2}{*}{$* \mathrm{NS}$} & $2(22,2 \%)$ & $7(77,8 \%)$ & \multirow{2}{*}{$* \mathrm{NS}$} \\
\hline Male & $37(59,7 \%)$ & $25(40,3 \%)$ & & $3(16,7 \%)$ & $15(83,3 \%)$ & \\
\hline \multicolumn{7}{|c|}{ Tumor localization } \\
\hline $1 / 3$ of up part & $3(50 \%)$ & $3(50 \%)$ & \multirow{3}{*}{$* \mathrm{NS}$} & $0(0 \%)$ & $2(100 \%)$ & \multirow{3}{*}{ *NS } \\
\hline $1 / 3$ of middle part & $20(52,6 \%)$ & $18(47,4 \%)$ & & $3(25 \%)$ & $9(75 \%)$ & \\
\hline $1 / 3$ of down part, all stomach & $30(63,8 \%)$ & $17(36,2 \%)$ & & $2(15,4 \%)$ & $11(84,6 \%)$ & \\
\hline \multicolumn{7}{|c|}{ Depth of invasion } \\
\hline Mucosa, submucosa & $9(75 \%)$ & $3(25 \%)$ & \multirow{3}{*}{$* \mathrm{NS}$} & $0(0 \%)$ & $0(0 \%)$ & \multirow{3}{*}{$* \mathrm{NS}$} \\
\hline Muscular layer & $13(72,2 \%)$ & $5(27,8 \%)$ & & $0(0 \%)$ & $3(100 \%)$ & \\
\hline Serosa & $31(50,8 \%)$ & $30(49,2 \%)$ & & $5(20,8 \%)$ & $19(79,2 \%)$ & \\
\hline \multicolumn{7}{|c|}{ Lauren's classification } \\
\hline Intestinal type & $36(59 \%)$ & $25(41 \%)$ & \multirow{2}{*}{$* \mathrm{NS}$} & $2(12 \%)$ & $15(88 \%)$ & \multirow{2}{*}{$* \mathrm{NS}$} \\
\hline Diffuse type & $17(56,7 \%)$ & $13(43,3 \%)$ & & $3(30 \%)$ & $7(70 \%)$ & \\
\hline \multicolumn{7}{|c|}{ Histological differentiation } \\
\hline G2 & $28(60,9 \%)$ & $18(39,1 \%)$ & \multirow{2}{*}{$* \mathrm{NS}$} & $1(8 \%)$ & $11(92 \%)$ & \multirow{2}{*}{ *NS } \\
\hline G3 & $25(55,6 \%)$ & $20(44,4 \%)$ & & $4(27 \%)$ & $11(73 \%)$ & \\
\hline \multicolumn{7}{|c|}{$\mathrm{pN}$} \\
\hline 1 & $0(0 \%)$ & $11(100 \%)$ & \multirow{3}{*}{0.0000} & $2(12.5 \%)$ & $14(87.5 \%)$ & \multirow{3}{*}{ *NS } \\
\hline 2 & $0(0 \%)$ & $17(100 \%)$ & & $3(30 \%)$ & $7(70 \%)$ & \\
\hline 3 & $0(0 \%)$ & $10(100 \%)$ & & $0(0 \%)$ & $1(100 \%)$ & \\
\hline
\end{tabular}

*NS - no statistical significence

between the 2nd - 32nd month. In the latter, death rate was increased at a similar time interval, i.e. between the 5th-26th month after surgery. The data were not statistically significant (Fig. 4).

\section{Discussion}

The process of metastasizing depends on the activity of various proteolytic enzymes, mainly proteases. In this process, cancer cells attach closely to each other, combine with laminin in the basement membrane, with thromboplastin or other agents, and in this way local proteolysis mediates permeation through the membrane. These mechanisms are frequently disturbed, being responsible for the tendency of cells to migrate and colonize distant organs. These processes are controlled by various enzymes, including degrading proteases, type IV collagenases and cathepsins [18].
Matrix metalloproteinase-9 (MMP-9) can degrade major complexes of the extracellular matrix (ECM), type IV collagen and gelatin, and therefore its activation is closely related to the invasive and metastatic capacity of cancer cells [16]. Considerably higher MMP-9 expression was found in stage II and III/IV according to Bormann classification than in stage I [28]. Zhang et al. [17] observed MMP-9 expression in $65.23 \%$ of gastric carcinoma patients, but found no relationship with tumor size and location or patients' gender. However, they observed a correlation between MMP-9 expression and tumor cell proliferation, depth of invasion, lymph node metastases or TNM stage of gastric carcinoma. Additionally, they noted that MMP9 expression increased in advanced carcinoma as compared to early stages. These results seem to indicate that MMP-9 expression plays a key role in the progression of gastric carcinoma and can thus be used as 
Table 2. Expression of cathepsin B and chosen clinical and pathological parameters in main mass of tumor and in lymph node metastasis.

\begin{tabular}{|c|c|c|c|c|c|c|}
\hline \multirow{2}{*}{ Parameters } & \multicolumn{3}{|c|}{ Expression of Cath B in main mass } & \multicolumn{3}{|c|}{$\begin{array}{l}\text { Expression of Cath B in lymph node } \\
\text { metastasis }\end{array}$} \\
\hline & Low $(n=57)$ & High $(n=34)$ & $\mathrm{p}$ & Low $(n=13)$ & $\operatorname{High}(n=13)$ & $\mathrm{p}$ \\
\hline \multicolumn{7}{|c|}{ Sex } \\
\hline Female & $15(51.7 \%)$ & $14(48.3 \%)$ & \multirow{2}{*}{ *NS } & $5(62.5 \%)$ & $3(37.5 \%)$ & \multirow{2}{*}{ *NS } \\
\hline Male & $42(67.7 \%)$ & $20(32.3 \%)$ & & $8(44.4 \%)$ & $10(55.6 \%)$ & \\
\hline \multicolumn{7}{|c|}{ Tumor localization } \\
\hline $1 / 3$ of up part & $4(66.7 \%)$ & $2(33.3 \%)$ & \multirow{3}{*}{ *NS } & $0(0 \%)$ & $2(100 \%)$ & \multirow{2}{*}{ *NS } \\
\hline $1 / 3$ of middle part & $24(63.2 \%)$ & $14(36.8 \%)$ & & $7(63.6 \%)$ & $4(36.4 \%)$ & \\
\hline $\begin{array}{l}1 / 3 \text { of down part, all } \\
\text { stomach }\end{array}$ & $29(61.7 \%)$ & $18(38.3 \%)$ & & $6(46.2 \%)$ & $7(53.8 \%)$ & \\
\hline \multicolumn{7}{|c|}{ Depth of invasion } \\
\hline Mucosa, submucosa & $9(75 \%)$ & $3(25 \%)$ & \multirow{3}{*}{0.05} & $0(50 \%)$ & $0(50 \%)$ & \multirow{3}{*}{${ }^{*} \mathrm{NS}$} \\
\hline Muscular layer & $15(83.3 \%)$ & $3(16.7 \%)$ & & $2(50 \%)$ & $2(50 \%)$ & \\
\hline Serosa & $33(54 \%)$ & $28(46 \%)$ & & $11(50 \%)$ & $11(50 \%)$ & \\
\hline \multicolumn{7}{|c|}{ Lauren's classification } \\
\hline Intestinal type & $38(62.3 \%)$ & $23(37.7 \%)$ & \multirow{2}{*}{ *NS } & $8(44.4 \%)$ & $10(55.6 \%)$ & \multirow{2}{*}{ *NS } \\
\hline Diffuse type & $19(63.3 \%)$ & $11(36.7 \%)$ & & $5(62.5 \%)$ & $3(37.5 \%)$ & \\
\hline \multicolumn{7}{|c|}{ Histological differentiation } \\
\hline G2 & $32(69.6 \%)$ & $14(30.4 \%)$ & \multirow{2}{*}{ *NS } & $4(36.4 \%)$ & $7(63.6 \%)$ & \multirow{2}{*}{${ }^{*} \mathrm{NS}$} \\
\hline G3 & $25(55.6 \%)$ & $20(44.4 \%)$ & & $9(60 \%)$ & $6(40 \%)$ & \\
\hline \multicolumn{7}{|c|}{$\mathrm{pN}$} \\
\hline 1 & $1(6.25 \%)$ & $15(93.75 \%)$ & \multirow{3}{*}{0.0000} & $7(50 \%)$ & $7(50 \%)$ & \multirow{3}{*}{ *NS } \\
\hline 2 & $0(0 \%)$ & $10(100 \%)$ & & $5(50 \%)$ & $5(50 \%)$ & \\
\hline 3 & $0(0 \%)$ & $1(100 \%)$ & & $0(0 \%)$ & $1(100 \%)$ & \\
\hline
\end{tabular}

*NS - no statistical significence

a marker of invasion [17]. We found the expression of MMP-9 in approximately $42 \%$ of cases and like other researchers we did not observe any relationship with such parameters as patients' gender or tumor location. Most frequently we found MMP-9 expression in tumors of intestinal-type in Lauren's classification, infiltrating the whole gastric wall, but contrary to some researches, in our study no significant correlations were noted. Similarly, in the case of cathepsin B, the expression was most common in the intestinal type tumors infiltrating the whole gastric wall, but no statistically significant correlations were observed. However, we noted a strong statistically significant association between cathepsin B expression and lymph node involvement, which is consistent with other literature reports $[29,30]$. Cathepsin B expression is related to the histological grade and TNM stage [29]. High cathepsin B expression correlates with depth of inva- sion in advanced rather than early (non-metastatic) stages. These data seem to indicate a relationship between gastric carcinoma malignancy and cathepsin $\mathrm{B}$ expression [30]. The expression of cathepsins may also correlate with the presence of distant metastases. Higher levels of cathepsin B, cathepsin L and UPA (urokinase-type plasminogen activator) have been observed in samples from patients with metastases to lymph nodes or liver, as compared to non-metastatic patients. The above results may confirm the correlation between the synthesis of cysteine and serine proteases and the potential tumor invasion [9].

Moreover, we demonstrated a strong association between MMP-9 expression and lymph node involvement. Also other authors observed a correlation of MMP-9 expression in gastric carcinoma with the presence of metastases in lymph nodes [23,17]. Endo et al. [31] reported that the levels of MMP-2 and MMP-9 in 

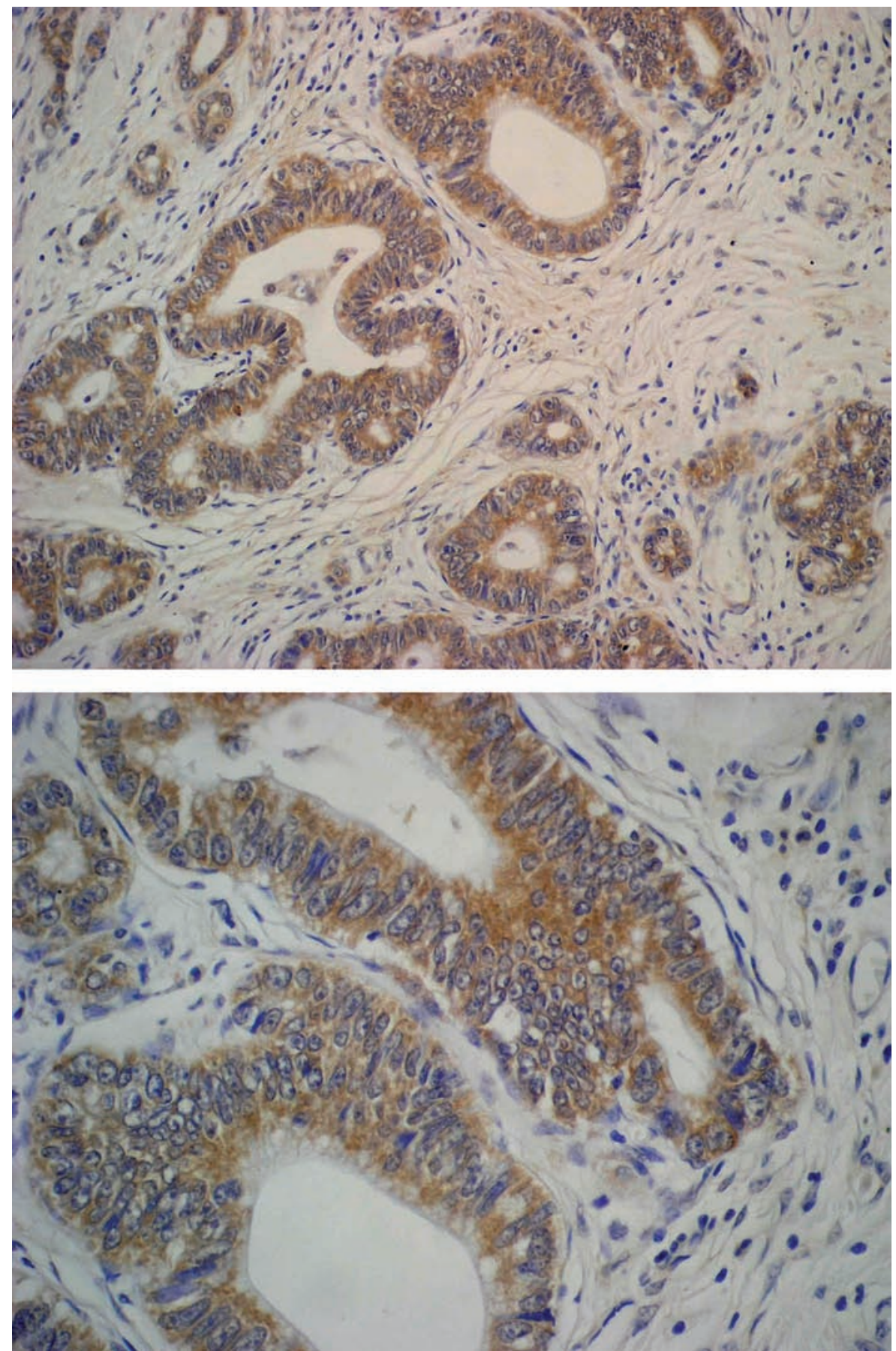

Fig. 1. Expression of MMP-9 in main mass of tumor.

Fig. 2. Expression of cathepsin B in main mass of tumor.

the serum and plasma were found to correlate with metastasis and invasion of gastric cancer. The expression of MMP-2 and MMP-9 has also been observed in early gastric carcinoma, but not found to correlate with lymph node metastasis or invasion depth $[3,32]$. However, Kabashima et al. [23] reported a statistically significant correlation between MMP-9, but not MMP-2, and lymph node involvement in IMGCs (intra mucosal gastric carcinoma). The activity of MMP-9 in the degradation of the basement membrane was approximately 25 times higher than that of MMP-2. Therefore,
MMP-9 can be considered a more sensitive factor for metastatic potential than MMP-2 [33,34].

The expression balance between MMP-9 and its TIMP-1 inhibitor plays a central role in the metastatic process. It has been found that the metastatic range in gastric cancer decreases markedly in the presence of MMP-9 and TIMP-1. This suggests that MMP-9 is involved in metastasis promotion, while TIMP-1 independently inhibits this process in gastric cancer [17].

It has been reported that gastric carcinomas of a more aggressive phenotype show increased synthesis 

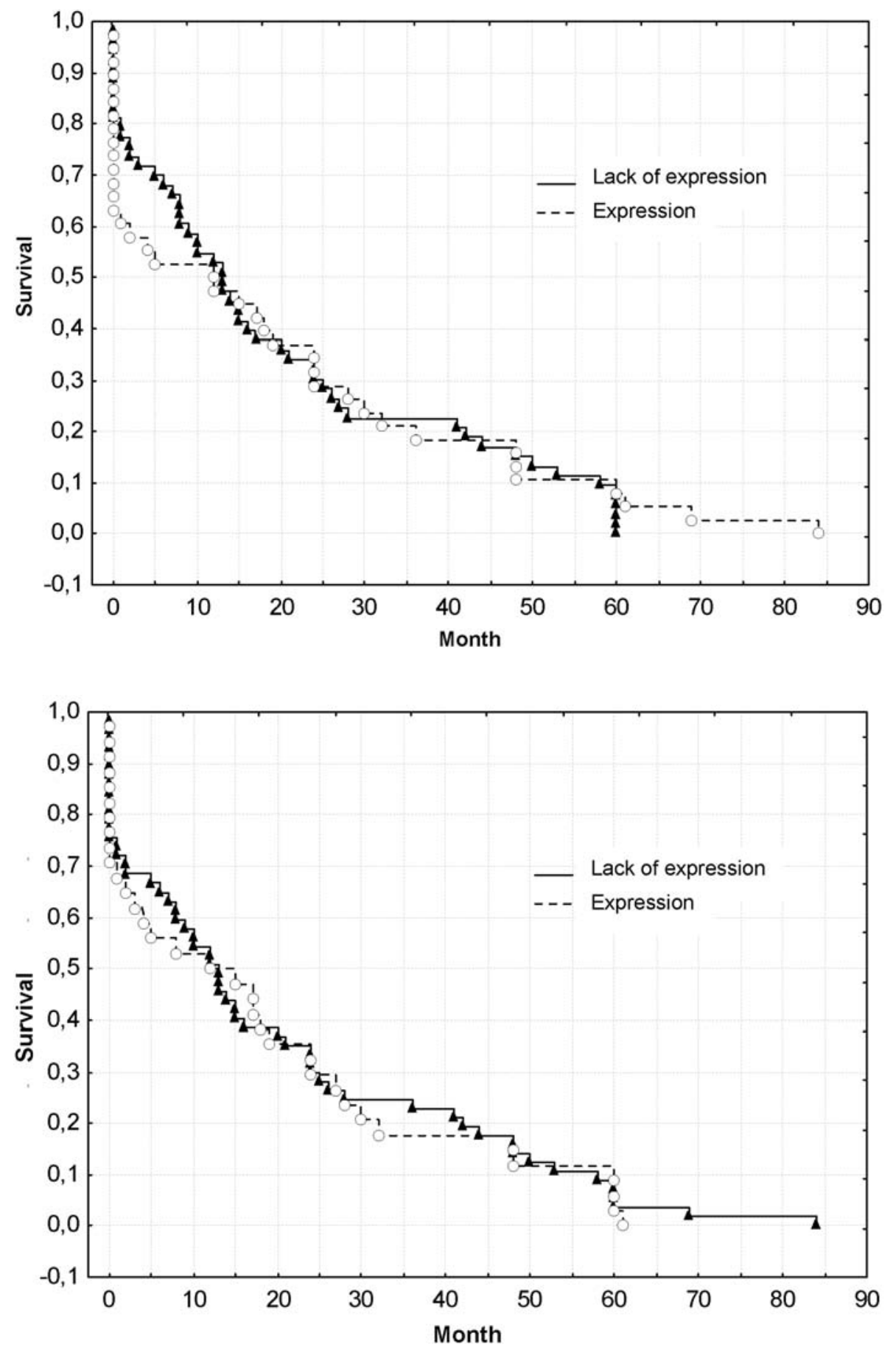

Fig. 3. Correlation of MMP9 protein expression in main mass of tumor with survival of patients with advanced gastric cancer.

Fig. 4. Correlation of cathepsin B protein expression in main mass of tumor with survival of patients with advanced gastric cancer.

of proteases. Herszeny et al. [35] found considerably higher values of cathepsin B in diffused gastric carcinoma as compared to the intestinal type. Patients with the scirrhus- infiltrate growth pattern (Borman typ IV) also had significantly high levels of cathepsin B, UPA and PAI-1 (plasminogen activator inhibitor type-1 antigen). Considerably higher levels of proteases have been observed in moderately- and low-differentiated tumors as compared to the well-differentiated ones. Moreover, it has been suggested that the increased cathepsin B expression accompanied by fragmentation of tumor-related laminin may play a role in tumor progression. A correlation has also been noted of cathepsin B expression with tumor stage and lymph node involvement [26].

The analysis of the mean survival time revealed that gastric cancer patients with high expression of cathepsin B had shorter survival rates (9 months), as compared to patients with poor or negative expression (16 months). We found no statistically significant cor- 
relation between a 5-year postoperative survival and tumor cathepsin B expression. However, as revealed by literature data, strong positive staining for cathepsin $\mathrm{B}$ correlates with more aggressive behavior of gastric carcinoma, which affects the postoperative survival and prognosis in patients after tumor resection $[35,36]$.

Sier et al. [37] has reported that the expression and activation of MMP-9 in cancer tissue has a prognostic value for shorter survival time of gastric carcinoma patients, irrespective of the main clinico-pathological parameters. Also Zhang et al. [17] have shown a significant relationship between MMP-9 and TIMP-1 expression and postoperative survival time of gastric carcinoma patients. They suggested that patients with MMP-9 over-expression and with no TIMP-1 expression had more aggressive tumor progression and shorter survival time [17]. We found a correlation between high MMP-9 expression in main mass of tumor and lymph node involvement. Moreover, patients with high expression of this protein had a considerably longer survival time as compared to the MMP-9 negative group (statistically insignificant data).

Concluding, our results indicate that MMP-9 and cathepsin B expression is associated with lymph node involvement in advanced gastric carcinoma, but not with postoperative survival time of patients. Additionally, cathepsin B expression is correlated with depth of invasion.

\section{References}

[1] Sier CF, Kubben FJ, Ganesh S, Heerding MM, Griffioen G, Hanemaaijer R, van Krieken JH, Lamers CB, Verspaget HW. Tissue levels of matrix metalloproteinases MMP-2 and MMP-9 are related to the overall survival of patients with gastric carcinoma. Br J Cancer. 1996;74:413-417.

[2] Hirano T, Yoshioka H. Serum cathepsin B levels, urinary excretion of cathepsin B and tissue cathepsin B content in the patients with gastric cancer. Arch Jpn Chir. 1993; 62:217-21.

[ 3] Nagase H, Woesser JF Jr. Matrix metalloproteinases. J Biol Chem. 1999;274:21491-494.

[ 4] Chung S, Kawai K. Protease activities in gastric cancer tissues. Clin Chim Acta. 1990;189:205-10.

[ 5] Murray GI, Duncan ME, O'Neil P, Melvin WT, Fothergill JE. Matrix metalloproteinase-1 is associated with poor prognosis in colorectal cancer. Nat Med. 1996;2:461-462.

[ 6] Berdowska I. Cysteine proteases as a disease markers. Clin Chim Acta. 2004;342: 41-69.

[ 7] Sun XM, Dong WG, Yu BP, Luo HS, Yu JP. Detection of type IV collagenase activity in malignant ascites. World $J$ Gastroenterol. 2003;9:2592-2595.

[ 8] Yamagata S, Tanaka R, Shimizu S. Gelatinases of murine metastatic tumor cells. Biochem Biophys Res Commun. 1989; 158:228-234.

[ 9] Russo A, Bazan V, Migliavacca M, Zanna I, Tubiolo C, Tumminello FM, Dardanoni G, Cajozzo M, Bazan P, Modica G, Latteri M, Tomasino RM, Colucci G, Gebbia N, Leto G. Prognostic significance of DNA ploidy, S-phase fraction, and tissue levels of aspartic, cysteine, and serine proteases in operable gastric carcinoma. Clin Cancer Res. $2000 ; 6: 178-84$.
[10] Pryczynicz A, Guzińska-Ustymowicz K, Dymicka-Piekarska V, Czyzewska J, Kemona A. Expression of matrix metalloproteinase 9 in pancreatic ductal carcinoma is associated with tumor metastasis formation. Folia Histochem Cytobiol. 2007; 45:37-40.

[11] Hujanen ES, Vaisanen A, Zheng A, Tryggvason K, Turpeenniemi-Hujanen T. Modulation of $\mathrm{M}(\mathrm{r}) 72,000$ and $\mathrm{M}(\mathrm{r})$ 92,000 type-IV collagenase (gelatinase A and B) gene expression by interferens alpha and gamma in human melanoma. Int J Cancer. 1994;58:582-586.

[12] Roa JS, Steck PA, Mohanam S, Stetler-Stevenson WG, Liotta LA, Sawaya R. Elevated levels of M(r) 92,000 type IV collagenase in human brain tumors. Cancer Res. 1993;53:22082211.

[13] Krepela E, Bartek J, Skalkova D, Vicgr J, Rasnick D, TaylorPapadimitriou J, Hallowes RC. Cytochemical and biochemical evidence of cathepsin B in malignant transformed and normal breast epithelial cells. J Cell Sci. 1987;87:145-154.

[14] Saleh Y, Siewinski M, Sebzda T, Jelen M, Ziolkowski P, Gutowicz J, Grybos M, Pawelec M. Inhibitoin of cathepsin B in human breast cancer tissue by cysteine peptidase inhibitor isolated from human placenta: immunohistochemical and biochemical studies. Folia Histochem Cytobiol. 2003;41:161-7.

[15] Torii A, Kodera Y, Uesaka K, Hirai T, Yasui K, Morimoto T, Yamamura Y, Kato T, Hayakawa T, Fujimoto N, Kito T. Plasma concentration of matrix metalloproteinase 9 in gastric cancer. Br J Surg. 1997;84:133-136.

[16] Rozhin J, Robinson D, Stevens MA, Lah TT, Hann KV, Ryan RE, Sloone BF. Properties of a plasma membrane-associated cathepsin B-like cysteine proteinase in metastatic B16 melanoma variants. Cancer Res. 1987;47:6620-6628.

[17] Stetler-Stevenson WG, Liotta LA, Kliener DE Jr. Extracellular matrix 6: role of matrix metalloproteinases in tumor invasion and metastasis. FASEB J. 1993;7:1434-1441.

[18] Duffy MJ. The role of proteolytic enzymes in cancer invasion and metastasis. Clin Exp Metastases. 1992;10:145-55.

[19] David L, Nesland JM, HolmR, Sobrinho-Simoes M. Expression of laminin, collagen IV, firbonectin and type IV collagenase in gastric carcinoma. An immunohistochemical study of 87 patients. Cancer. 1994;73:518-527.

[20] Higashiyama M, Doi O, Kodama K, Yokouchi H, Tateishi R. Cathepsin B expression in tumor cells and laminie distribution in pulmonary adenocarcinoma. J Clin Pathol. 1993;46: 18-22.

[21] Dohchin A, Suzuki JI, Seki H, Masutani M, Siroto H, Kawakami Y. Immunostained cathepsins B and L correlate with depth of invasion and different metastatic pathaways in early gastric carcinoma. Cancer. 2000;89:482-87.

[22] Kabashima A, Maehera Y, Kakeji Y, Baba H, Koga T, Sugimachi K. Clinicopathological features and overexpression of matrix matalloproteinases in intramucosal gastric carcinoma with lymph node metastasis. Clin Cancer Res. 2000;6: 35813584.

[23] Kallakury BV, Karikehalli S, Haholu A, Sheehan CE, Azumi N, Ross JS. Increased expression of matrix metalloproteinases 2 and 9 and tissue inhibitors of metalloproteinases 1 and 2 correlate with poor prognostic variables in renal cell carcinoma. Clin Cancer Res. 2001;7:3113-3119.

[24] Schwartz MK. Tissue cathepsins as tumor markers. Clin Chim Acta. 1995;237:67-78.

[25] Yasumitu H, Miyazaki K, Umenishi F, Koshikawa N, Umeda M. Comparision of extracellular matrix- degradating activities between $64-\mathrm{kDa}$ and $90-\mathrm{kDa}$ gelatinases purified in inhibitor- free forms from human schwannoma cells. $J$ Biochem. 1992;111: 74-80.

[26] Khan A, Krishna M, Baker SP, Banner BF. Cathepsin B and tumor associated laminie expression in colorectal adenoma and carcinoma. Mod Pathol. 1997;10:57A. Abstract. 
[27] Murphy G, Docherty AJ. The matrix metalloproteinases and their inhibitors. Am J Resp Cell Mol Biol. 1992;7:120-125.

[28] Ko BK, Cho HR, Choi DR, Nam CW, Kim GY, Kiss SS, Woo YJ, Huh J, Kim MY. Reduced expression of tissue inhibitor of metalloproteinase in nodal metastasis of stomach cancer. $J$ Korean Med Sci. 1998;13:286-290.

[29] Zhang S, Li L, Lin JY Lin H. Imbalance between expression of matrix metalloproteinase- 9 and tissue inhibitor of metalloproteinase- 1 in invasiveness and metastasis of human gastric carcinoma. World J Gastroenterol. 2003;9:899-904.

[30] Herszeny L, Plebani M, Carraro P, De Paoli M, Roveroni G, Cardin R, Foschia F, Tulassay Z, Naccarato R, Farinati F. Proteases in gastrointestinal neoplastic disease. Clin Chim Acta. 2000;171-187.

[31] Chicoine E, Esteve PO, Roblebo O, Van Themsche C, Potworowski EF, St-Pierre Y. Evidence for the role of promoter methylation in the regulation of MMP-9 gene expression. Biochem Biophys Res Commun. 2002;297:765-772.

[32] Sehgal I, Baley PA, Thompson TC. Transforming growth factor beta 1 stimulates contrasting responses in metastatic ver- sus primary mouse prostate cancer-derived cell lines in vitro. Cancer Res. 1996;56:3359-3365.

[33] Parsons SL, Watson SA, Brown PD, Collins HM, Steele RJ. Matrix metalloproteinases. Br J Surg. 1997;84:160-166.

[34] Endo K, Maedera Y, Baba H, Yamamoyo M, Tomisaki S, Watanabe A, Kakeji Y, Sugimachi K. Elevated levels of serum and plasma metalloproteinases in patients with gastric cancer. Anticancer Res. 1997;17:2253-2258.

[35] Vasisha A, Baker PR, Hopwood D, Holley PM, Cuschieri A. Proteinase-like peptidase in malignant and non-malignant gastric tissue. Br J Surg. 1985;72:386-8.

[36] Woessner JF Jr. Matrix matalloproteinases and their inhibitors in connective tissue remodeling. FASEB J. 1991;5: 2145-2154

[37] Liu Y, Ciao S, Shi Y, Wang L, Ren W, Sloane BF. Cathepsin $\mathrm{B}$ on invasion and metastasis of gastric carcinoma. Chin Med J (Engl). 1998;111:784-8.

Submitted: 1 April, 2007 Accepted after reviews: 5 October, 2007 